\title{
Clinical Characteristics and Outcome of Pathologic N0 Non-small Cell Lung Cancer Patients With False Positive Mediastinal Lymph Node Metastasis on FDG PET-CT
}

\author{
KYU YEAN KIM ${ }^{1 *}$, HYE LIM PARK ${ }^{2 *}$, HYE SEON KANG ${ }^{1}$, HWA YOUNG LEE ${ }^{1}$, \\ IE RYUNG YOO $^{3}$, SANG HAAK LEE ${ }^{1}$ and CHANG DONG YEO ${ }^{1}$ \\ ${ }^{1}$ Division of Pulmonology, Allergy and Critical Care Medicine, Department of Internal Medicine, \\ College of Medicine, The Catholic University of Korea, Seoul, Republic of Korea; \\ ${ }^{2}$ Division of Nuclear Medicine, Department of Radiology, Eunpyeong St. Mary's Hospital, \\ College of Medicine, The Catholic University of Korea, Seoul, Republic of Korea; \\ ${ }^{3}$ Division of Nuclear Medicine, Department of Radiology, Seoul St. Mary's Hospital, \\ College of Medicine, The Catholic University of Korea, Seoul, Republic of Korea
}

\begin{abstract}
Background/Aim: Preoperative fluorine-18 fluorodeoxyglucose positron emission tomography/computed tomography (FDG PET-CT) is a non-invasive and useful diagnostic tool to evaluate mediastinal lymph node ( $L N)$ metastasis in lung cancer. However, there are often falsepositive LN cases in FDG PET-CT. This study aimed to explore the clinical characteristics and outcome of pathologic NO non-small cell lung cancer patients with falsepositive mediastinal LN on FDG PET-CT. Patients and Methods: We enrolled 147 patients who underwent preoperative FDG PET-CT scan and mediastinal LN dissection. These patients were re-evaluated for post-operative pathologic nodal metastasis and divided into a false-positive group and a group of others. Results: Among 40 patients diagnosed with clinical N1-3 on FDG PET-CT, 19 (47.5\%) patients were pathologic NO, meaning false-positive $L N$ by PET-CT. Preoperative absolute platelet count and plateletlymphocyte ratio were significantly higher in patients with pathologic NO. The presence of lymphatic invasion was significantly lower in patients with pathologic NO than in the
\end{abstract}

This article is freely accessible online.

*These Authors contributed equally to this work.

Correspondence to: Chang Dong Yeo, MD, Ph.D., Division of Pulmonary, Allergy and Critical Care Medicine, Department of Internal Medicine, College of Medicine, Eunpyeong St Mary's Hospital, The Catholic University of Korea, 1021, Tongil Ro, Eunpyeong-gu, Seoul, Republic of Korea. Tel: +82 220204340, e-mail: brainyeo@catholic.ac.kr

Key Words: Lung cancer, FDG PET-CT, false-positive. group of others. Recurrence-free survival was significantly shorter in patients with false positive $L N$ than in patients with true positive $L N$ or true negative $L N$ at the same pathologic stage. Conclusion: Higher absolute platelet count and PLR, lower proportion of lymphatic invasion and shorter recurrence-free survival were associated with false positive mediastinal LN on preoperative FDG PET-CT.

Lung cancer is the most common cause of cancer death worldwide (in both developing and developed countries) (1). In Korea, lung cancer has also been the leading cause of cancer death since 1999. The age-standardized mortality rate of lung cancer in the Korean population was 23.3 per 100,000 in 2014 (2). Although mortality from lung cancer is very high, it has been improving recently due to screening with low-dose computed tomography (CT) (3). Early detection and accurate TNM staging are crucial for the prognosis of lung cancer patients. For patients with nonsmall cell lung cancer (NSCLC) without extrathoracic metastasis, mediastinal lymph node (LN) staging is very essential as it provides accurate information on the extent of the disease. It also guides the choice of treatment and determines a patient's prognosis (4).

Preoperative fluorine-18 fluorodeoxyglucose positron emission tomography/computed tomography (FDG PET-CT) is a non-invasive and useful diagnostic tool to evaluate mediastinal LN metastasis in lung cancer. Based on American College of Chest Physicians (ACCP) evidencedbased clinical practice guidelines, the sensitivity and specificity of the CT scan for evaluating mediastinal metastasis were $51 \%$ and $85 \%$, respectively. For FDG PETCT, sensitivity and specificity were $74 \%$ and $85 \%$, respectively (5). Because FDG uptake is not completely 


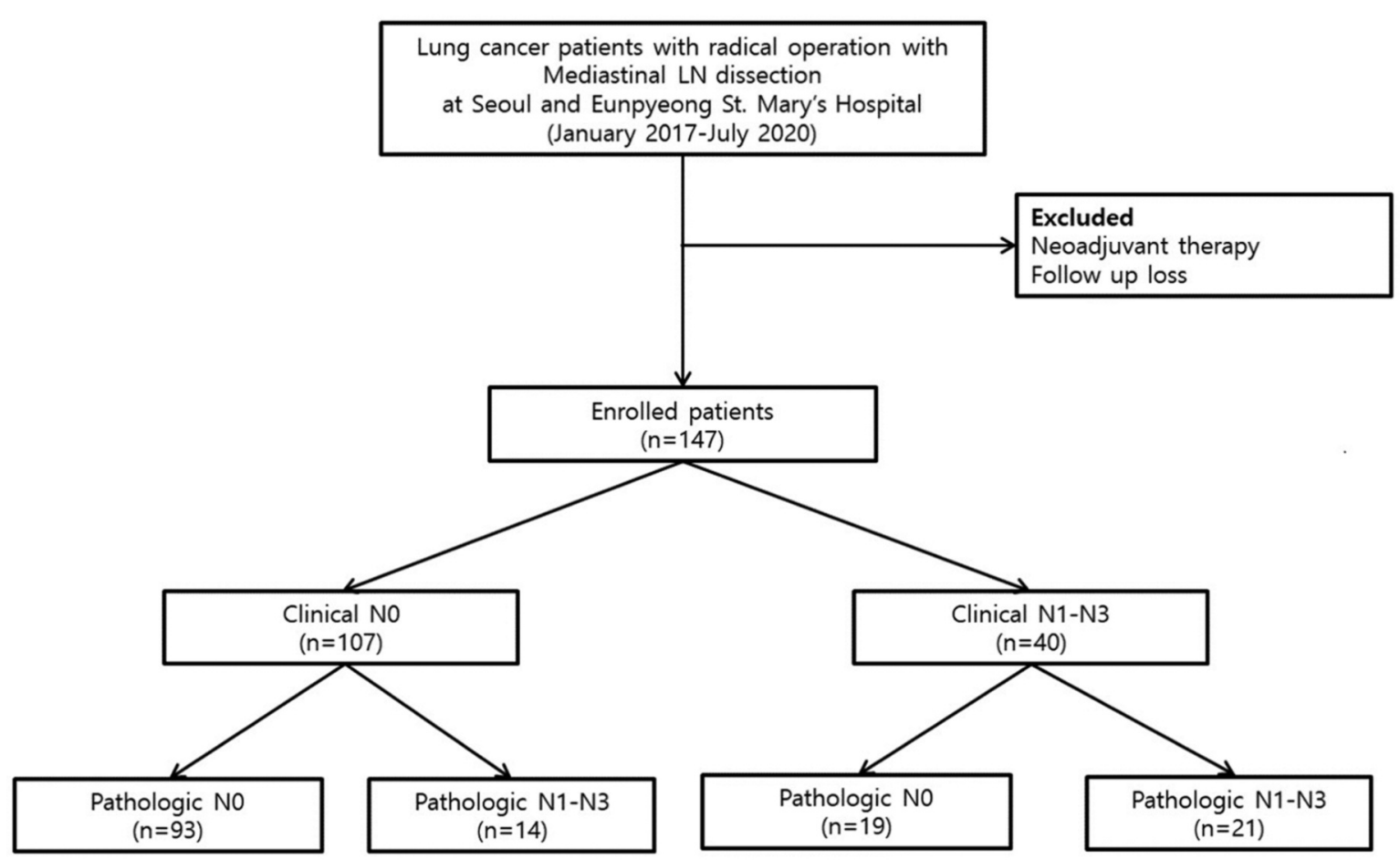

Figure 1. Study flow diagram.

specific for cancer cells, there are often false-positive LN cases. To complement this disadvantage, we usually perform endobronchial ultrasound (EBUS) or mediastinoscopy for pathologic mediastinal LN confirmation in clinical settings. The diagnostic yield of EBUS-guided transbronchial needle aspiration (EBUS-TBNA) is relatively high, with a sensitivity of approximately $88 \%$ and a specificity of $100 \%$ (6). This is a minimally invasive method with few procedure-related complications. It is also easy to approach lesions adjacent to the central airway. Regarding surgical mediastinoscopy, its sensitivity and specificity have been reported to be $81.3 \%$ and $100 \%$, respectively (6). However, mediastinoscopy is used in limited cases due to its invasiveness. Despite the recent introduction of EBUSTBNA, pathologic nodal staging of lung cancer could still be changed, leading to downstaging in $16 \%$ and upstaging in $9.75 \%$ of patients (7). Therefore, it is very essential to evaluate the probability of false-positive and false-negative in FDG PET-CT before treatment.

To date, false-positive LN on FDG is common in concurrent inflammatory lung diseases or centrally located tumors because glucose is also avidly metabolized by tissues involved in granulomatous or inflammatory processes (8). SUVmax and size of primary tumor, adenocarcinoma, small size of metastatic foci, low cellularity, and low glucose transporter expression can lead to false-negative findings on FDG PET-CT (9-11). False-negative PET findings could also be observed in hyperglycemia patients. Hyperglycemia can prevent FDG uptake in the tumor because of a competitive reaction (12). Due to diagnostic limitations of PET-CT, falsepositive and false-negative results of lymph node metastasis could lead to inappropriate treatment decisions, thus emphasizing the importance of precise evaluation of mediastinal lymph nodal stage. An association between maximum standardized uptake value (SUV - max) measured on FDG PET-CT and prognosis of non-small cell lung cancer has also been previously reported (13). However, studies on clinicopathologic factors associated with FDG uptake of PET-CT are scarce.

Thus, the aim of this study was to explore pretreatment clinicopathologic characteristics and prognostic factors of pathologic N0 non-small cell lung cancer (NSCLC) patients with false-positive mediastinal lymph nodes on FDG PET-CT.

\section{Patients and Methods}

Patient selection. From January 2017 to July 2020, patients with lung cancer who underwent pre-operative PET-CT and mediastinal LN dissection at Seoul St. Mary's Hospital and Eunpyeong St. Mary's Hospital of Catholic Medical Center were recruited. We retrospectively analyzed pathologically proven NSCLC patients diagnosed with clinical N1-3 on FDG PET-CT, but pathologic N0 after mediastinal LN dissection. Staging was based on the $8^{\text {th }}$ edition of the American Joint Commission on Cancer TNM staging system for non-small cell lung cancer. 
We routinely conducted pathologic nodal confirmation with EBUS-TBNA or mediastinoscopy for patients with mediastinal LNs $>1 \mathrm{~cm}$ or a hypermetabolic state in FDG PET-CT. Patients with central tumors or clinical N1 LN involvement on FDG PET-CT or CT were also indicated for pathologic nodal confirmation (14). Patients who were pathologically confirmed with mediastinal nodal metastasis by EBUS-TBNA or mediastinoscopy and underwent neoadjuvant treatment, were excluded from this study. Patients under 18 years old and those who did not have follow-up visits were also excluded. The flow chart of patient selection is shown in Figure 1. A total of 147 NSCLC patients were enrolled. Among them, 40 patients were diagnosed with clinical N1-3 by FDG PET-CT. These 40 patients were then divided into a pathologic N0 group (falsepositive) and a pathologic N1-N3 group (true-positive) (Figure 1).

FDG PET-CT protocol and image analysis. All patients underwent FDG PET-CT before surgery. FDG PET-CT images were acquired using a combined PET-CT in-line system (Biograph mCT, Biograph Vision 600, Siemens Medical Solutions, Knoxville, TN, USA). All patients fasted for at least $6 \mathrm{~h}$ before FDG PET-CT. At 60 min after intravenous injection of fluorine-18 fluorodeoxyglucose (3.7 4.4 $\mathrm{MBq} / \mathrm{kg}$ for Biograph $\mathrm{mCT}$ and $1.85 \mathrm{MBq} / \mathrm{kg}$ for Biograph Vision 600), PET-CT images were acquired. Biograph mCT images were acquired at 2 min per bed position. Biograph Vision 600 images were acquired with FlowMotion ${ }^{\mathrm{TM}}$ and $1.5 \mathrm{~mm} / \mathrm{s}$

All FDG PET-CT images were independently reviewed by two experienced nuclear medicine physicians (HL Park and IR Yoo, both with over 10 years of experience in lung cancer using XD3, Mirada Medical, Oxford, UK). In case of disagreement, consensus was reached after discussion. Metastatic LN on PET images was defined as higher FDG uptake than mediastinal blood pool activity (aortic arch level) with an asymmetric distribution.

Definition of clinical factors. History of smoking was recorded based on patient's statement. Never smokers were defined as patients who had never smoked or smoked fewer than 100 cigarettes lifelong. Current smokers were defined as patients who reported that they continued to smoke or stopped smoking less than 6 months before the diagnosis of lung cancer. History of tuberculosis was also investigated based on patient's statement. Patients who had never been diagnosed with tuberculosis were defined as "Tuberculosis Negative". Patients who had been diagnosed with tuberculosis in the past were defined as "Tuberculosis Positive". We also evaluated concomitant radiologic presence of infection or inflammation by agreement between pulmonologists (KY Kim, CD Yeo) and nuclear medicine radiologist (HL Park) according to results of chest $\mathrm{CT}$ and PET-CT scan.

Laboratory tests. Preoperative complete blood count (CBC) was obtained for enrolled patients using blood samples collected within 14 days prior to operation. Neutrophil-lymphocyte ratio (NLR) was calculated by dividing the number of neutrophil counts by the number of lymphocyte counts. Platelet-lymphocyte ratio (PLR) was calculated by dividing the number of platelet counts by the number of lymphocyte counts.

Pathologic study. We investigated differentiation, visceral-pleural invasion (VPI), lymphatic invasion (LI) and programmed deathligand 1 (PD-L1) tumor proportion score (TPS), and genetic alterations in epidermal growth factor receptor (EGFR) and anaplastic lymphoma kinase (ALK). EGFR mutation was examined using a PNAClamp ${ }^{\mathrm{TM}}$ EGFR Mutation Detection Kit (PANAGENE, Inc., Daejeon, Korea) and real-time PCR (15). ALK translocation was determined by fluorescent in situ hybridization (FISH) and analyzed in the central molecular laboratory of Yeouido St. Mary's Hospital. The sample was considered ALK positive when more than $15 \%$ of counted nuclei in tumor cells exhibited split signals or an isolated red signal (16). PD-L1 TPS was the percentage of viable tumor cells showing partial or complete membranous staining at any intensity. PD-L1 immunohistochemistry was performed using PD-L1 IIIC 22C3 pharmDx assay kit (Agilent/Dako, Santa Clara, CA, USA). PD-L1 expression was subclassified as high PD-L1 expression (TPS $\geq 50 \%$ ) and low PD-L1 expression (1\% $\leq$ TPS $<50 \%)(17)$.

Recurrence-free survival. After curative operation, CT was routinely performed to check for recurrence of lung cancer. A cancer recurrence was defined as cancer that relapsed either radiographically or histologically after treatment. Recurrences were evaluated by treating pulmonologists and independent radiologists. Recurrence-free survival was defined as the time (month) from the date of operation to the date of recurrence or the date of the last follow up.

Statistical analysis. Comparison between the pathologic N0 group and the pathologic N1-N3 group was performed using Student's $t$ test for continuous variables and Chi-square test for categorical variables. Correlations between false-positivity of mediastinal lymph node and clinicopathologic variables were analyzed by logistic regression analysis. To investigate the prognosis of patients, comparison between the pathologic N0 group and the group of others was analyzed by Kaplan-Meier curve and log-rank test. Cox multivariate proportional hazard analysis was performed to identify significant clinicopathologic features associated with recurrence-free survival. All statistical analyses were performed using SPSS version 20.0 (SPSS, Chicago, IL, USA).

Ethical statement. The study was approved by the Institutional Review Board (approval number: XC20RIDI0148P) of the Catholic University of Korea, Catholic Medical Center. The requirement for informed consent was waived because the study was retrospective in nature and all data were anonymized.

\section{Results}

Patient characteristics. Among a total of 147 patients, 107 were diagnosed with clinically N0 by FDG PET-CT. Among 40 patients who were diagnosed with clinical N1-3 on FDG PET-CT, 19 (47.5\%) patients were pathologic N0, meaning false-positive LN by PET-CT. Baseline clinicopathologic characteristics of each group are shown in Table I. There was no significant difference in age, gender, smoking status, or underlying diseases (such as tuberculosis and diabetes mellitus) between the pathologic NO group and the group of others. Concomitant infection or inflammation was not a significant factor for differentiating pathologic NO from pathologic N1-N3 (Table I).

In preoperative laboratory results, absolute platelet count $(279,790 / \mu \mathrm{l} \pm 83,600$ versus $218,670 / \mu \mathrm{l} \pm 44,500 ; p=0.012)$ and 
Table I. Baseline clinicopathologic characteristics of patients in pNO and pN1-N3 groups.

\begin{tabular}{|c|c|c|c|}
\hline Parameters & $\mathrm{pN} 0(\mathrm{n}=19)$ & $\mathrm{pN} 1-3(\mathrm{n}=21)$ & $p$-Value \\
\hline Age & $70.1 \pm 7.2$ & $68.4 \pm 6.6$ & 0.532 \\
\hline \multicolumn{4}{|l|}{ Gender } \\
\hline Male & $17(89.5 \%)$ & $14(66.7 \%)$ & 0.133 \\
\hline Female & $2(10.5 \%)$ & $7(33.3 \%)$ & \\
\hline Smoking & & & 0.186 \\
\hline Never & $1(5.3 \%)$ & $5(23.8 \%)$ & \\
\hline Current+Former & $18(94.7 \%)$ & $16(76.2 \%)$ & \\
\hline Tuberculosis & & & 1.0 \\
\hline Negative & $16(84.2 \%)$ & $18(85.7 \%)$ & \\
\hline Positive & $3(15.8 \%)$ & $3(14.3 \%)$ & \\
\hline DM & & & 0.385 \\
\hline Negative & $15(78.9 \%)$ & $14(66.7 \%)$ & \\
\hline Positive & $4(21.1 \%)$ & $7(33.3 \%)$ & \\
\hline Inflammation on CT scan & & & 0.473 \\
\hline Negative & $13(68.4 \%)$ & $17(81.0 \%)$ & \\
\hline Positive & $6(31.6 \%)$ & $4(19.0 \%)$ & \\
\hline WBC $\left(\times 10^{9} / 1\right)$ & $6,725.3 \pm 2,090.5$ & $6,608.6 \pm 1,651.2$ & 0.903 \\
\hline Neutrophil (\%) & $56.4 \pm 13.4$ & $56.7 \pm 10.4$ & 0.914 \\
\hline Lymphocyte (\%) & $29.3 \pm 11.4$ & $32.5 \pm 10.1$ & 0.350 \\
\hline Platelet $($ per $/ \mu \mathrm{l})$ & $279,790 \pm 83,600$ & $218,670 \pm 44,500$ & 0.012 \\
\hline NLR & $2.4 \pm 1.4$ & $2.1 \pm 1.1$ & 0.579 \\
\hline PLR & $16.9 \pm 7.3$ & $11.5 \pm 4.1$ & 0.012 \\
\hline Tumor Size $(\mathrm{cm})$ & $4.04 \pm 1.88$ & $3.60 \pm 2.37$ & 0.516 \\
\hline Op & & & 1.0 \\
\hline Lobectomy & $19(100.0 \%)$ & $20(95.2 \%)$ & \\
\hline Sublobar resection & $0(0.0 \%)$ & $1(4.8 \%)$ & \\
\hline Histology & & & 0.468 \\
\hline Adenocarcinoma & $10(52.6 \%)$ & $14(66.7 \%)$ & \\
\hline $\mathrm{SqCC}$ & $8(42.1 \%)$ & $5(23.8 \%)$ & \\
\hline Others & $1(5.3 \%)$ & $2(9.5 \%)$ & \\
\hline $\mathrm{cN}$ stage & & & 0.894 \\
\hline N1 & $11(57.9 \%)$ & $12(57.1 \%)$ & \\
\hline $\mathrm{N} 2$ & $6(31.6 \%)$ & $8(38.1 \%)$ & \\
\hline N3 & $2(10.5 \%)$ & $1(4.8 \%)$ & \\
\hline \multicolumn{4}{|l|}{$\mathrm{pN}$ stage } \\
\hline N1 & 0 & $10(47.6 \%)$ & \\
\hline N2 & 0 & $10(47.6 \%)$ & \\
\hline N3 & 0 & $1(4.8 \%)$ & \\
\hline Differentiation & & & 0.935 \\
\hline WD & 0 & 0 & \\
\hline MD & $12(63.2 \%)$ & $13(61.9 \%)$ & \\
\hline PD & $7(36.8 \%)$ & $8(38.1 \%)$ & \\
\hline Lymphatic invasion & & & 0.001 \\
\hline Absent & $13(68.4 \%)$ & $3(14.3 \%)$ & \\
\hline Present & $6(31.6 \%)$ & $18(85.7 \%)$ & \\
\hline Visceral-pleural invasion & & & 1.0 \\
\hline Absent & $16(84.2 \%)$ & $17(81.0 \%)$ & \\
\hline Present & $3(15.8 \%)$ & $4(19.0 \%)$ & \\
\hline EGFR & & & 0.186 \\
\hline Negative & $18(94.7 \%)$ & $16(76.2 \%)$ & \\
\hline Positive & $1(5.3 \%)$ & $5(23.8 \%)$ & \\
\hline ALK & & & 1.0 \\
\hline Negative & $19(100.0 \%)$ & $20(95.2 \%)$ & \\
\hline Positive & $0(0.0 \%)$ & $1(4.8 \%)$ & \\
\hline PD-L1 TPS & & & 0.501 \\
\hline $0 \sim 49 \%$ & $12(70.6 \%)$ & $12(60.0 \%)$ & \\
\hline$\geq 50 \%$ & $5(29.4 \%)$ & $8(40.0 \%)$ & \\
\hline Recur & & & 0.906 \\
\hline No & $13(68.4 \%)$ & $14(66.7 \%)$ & \\
\hline Yes & $6(31.6 \%)$ & $7(33.3 \%)$ & \\
\hline Death & & & 0.345 \\
\hline No & $18(94.7 \%)$ & $17(81.0 \%)$ & \\
\hline Yes & $1(5.3 \%)$ & $4(19.0 \%)$ & \\
\hline
\end{tabular}

DM: Diabetes mellitus; NLR: neutrophil-lymphocyte ratio; PLR platelet-lymphocyte ratio; EGFR: epidermal growth factor receptor; ALK: anaplastic lymphoma kinase; TPS: tumor proportion score.
PLR (16.9 \pm 7.3 versus $11.5 \pm 4.1 ; p=0.012)$ were significantly higher in pathologic N0 patients compared to $\mathrm{pN} 1-3$ patients (Table I). There was no statistically significant difference in white blood cell count, the proportion of neutrophils, the proportion of lymphocytes, or NLR. Among pathologic findings, the presence of lymphatic invasion was significantly lower in pathologic N0 patients than in the group of others (31.6\% versus $85.7 \%$; $p=0.001$; Table I). However, there was no significant difference in the presence of visceral pleural invasion, tumor size, method of operation, histologic type, or the degree of differentiation. EGFR, ALK, and PD-L1 TPS were not statistically significant factors of pathologic N0.

Six $(31.6 \%)$ patients in the pNO group and seven $(33.3 \%)$ patients in the pN1-N3 group were confirmed to have recurrence, showing no significant difference between the two groups. One $(5.3 \%)$ patient in the pN0 group and four $(19.0 \%)$ patients in the pN1-N3 group died, showing no significant difference between the two groups.

Factors associated with false-positive mediastinal lymph node. In univariate analysis, high PLR and no lymphatic invasion were statistically significant factors associated with false-positive mediastinal LN. In multivariate analysis, higher $\operatorname{PLR}(p=0.022)$ and no lymphatic invasion $(p=0.003)$ were significant factors for false-positive LN metastases. Age, gender, smoking status, and presence of EGFR mutation failed to be significant factors for false-positivity (Table II).

Factors associated with recurrence-free survival. Among a total of 147 patients, 44 patients were in stage II (6 patients with false-positive LN, 17 with true-negative LN, 9 with true-positive LN, and 12 with false-negative LN). The time of recurrence-free survival was significantly shorter for patients with false-positive LN than for patients with truepositive $\mathrm{LN}$ or true-negative $\mathrm{LN}$ in pathologic stage II ( $p=0.018$, log-rank test; Figure 2). The mean time to recurrence after operation was 7.9 months for the pathologic N0 group and 24.0 months for the pathologic N1-N3 group. The recurrence difference was significant at 6 months (50.0\% vs. $22.2 \%$ ). Results showed that patients with falsepositive LN had poorer recurrence-free survival than patients with true-positive LN or true-negative LN.

Cox multivariate proportional hazard analysis showed that smoking status and lymphatic invasion were independent prognostic factors for recurrence-free survival (Table III). However, age, PLR, and false-positivity were not relevant factors for recurrence-free survival.

\section{Discussion}

In the present study, higher absolute platelet count, higher PLR, and lower proportion of lymphatic invasion were associated with false-positive mediastinal $\mathrm{LN}$ on 
Table II. Results of univariate and multivariate logistic regression analyses for false-positive mediastinal lymph node.

\begin{tabular}{|c|c|c|c|c|c|c|c|}
\hline \multirow[b]{2}{*}{ Variables } & \multirow[b]{2}{*}{ Category } & \multicolumn{3}{|c|}{ Univariate } & \multicolumn{3}{|c|}{ Multivariate } \\
\hline & & OR & $95 \% \mathrm{CI}$ & $p$-Value & OR & $95 \% \mathrm{CI}$ & $p$-Value \\
\hline Age & & 1.031 & $0.90-1.18$ & 0.648 & & & \\
\hline Gender & Female vs. Male (Ref.) & 2.904 & $0.14-58.70$ & 0.487 & & & \\
\hline \multirow[t]{2}{*}{ Smoking } & Ever-smoker $v s$ & & & & & & \\
\hline & Never-smoker (Ref.) & 60.561 & $0.88-4187.21$ & 0.058 & 14.79 & $0.77-283.52$ & 0.074 \\
\hline PLR & & 1.342 & 1.04-1.73 & 0.024 & 1.271 & $1.04-1.56$ & 0.022 \\
\hline Lymphatic & Lymphatic invasion $(+)$ & & & & & & \\
\hline invasion & vs. Lymphatic invasion (-) (Ref.) & 0.014 & $0.00-0.25$ & 0.003 & 0.023 & $0.00-0.29$ & 0.003 \\
\hline EGFR & EGFR (+) vs. EGFR (-) (Ref.) & 3.028 & $0.18-49.82$ & 0.438 & & & \\
\hline
\end{tabular}

PLR: Platelet-lymphocyte ratio; EGFR: epidermal growth factor receptor.

Table III. Cox multivariate proportional hazard analysis on recurrence-free survival.

\begin{tabular}{|c|c|c|c|c|}
\hline Variables & Category & $\mathrm{HR}$ & $95 \% \mathrm{CI}$ & $p$-Value \\
\hline Age & & 0.986 & $0.893-1.088$ & 0.776 \\
\hline Smoking & Ever-smoker $v s$ & & & \\
\hline & Never-smoker (Ref.) & 5.069 & $1.033-24.866$ & 0.045 \\
\hline PLR & & 1.012 & $0.929-1.101$ & 0.791 \\
\hline Lymphatic invasion & $\begin{array}{l}\text { Lymphatic invasion (+) } \\
\text { vs. Lymphatic invasion (-) (Ref.) }\end{array}$ & 4.814 & $1.024-22.622$ & 0.047 \\
\hline $\begin{array}{l}\text { False-positive } \\
\text { LN }\end{array}$ & $\begin{array}{l}\text { False-positive LN } \\
\text { vs. Others (Ref.) }\end{array}$ & 1.029 & $0.216-4.893$ & 0.971 \\
\hline
\end{tabular}

PLR: Platelet-lymphocyte ratio; LN: lymph node.

preoperative FDG PET-CT. Patients with false-positive LN had shorter recurrence-free survival than patients with truepositive $\mathrm{LN}$ or true-negative $\mathrm{LN}$ in the same pathologic stage. The aim of our study was to elucidate clinicopathologic factors of NSCLC patients with falsepositive LN on FDG PET-CT.

Platelets can affect tumor microenvironment by supporting cancer stem cells, sustaining proliferative signals, inducing angiogenesis, and mediating resistance to cell death and evasion immune detection (18). Several studies have reported that elevated platelet count is associated with poor prognosis in lung cancer $(19,20)$. PLR is also known to be an inflammatory marker and prognostic biomarker in NSCLC according to recent studies (21). Patients with advanced NSCLC with malignant effusion and high PLR have shorter survival (22). Moreover, high PLR can predict poor response to first-line chemotherapy (23). High PLR means increased platelet counts and decreased lymphocyte counts, which could also impact tumor development (24).

One study has analyzed the relationship between tumor hematologic prognostic indicators and FDG uptake in stage I lung cancer patients following curative resection (25). In that study, patients with high tumor SUV max had

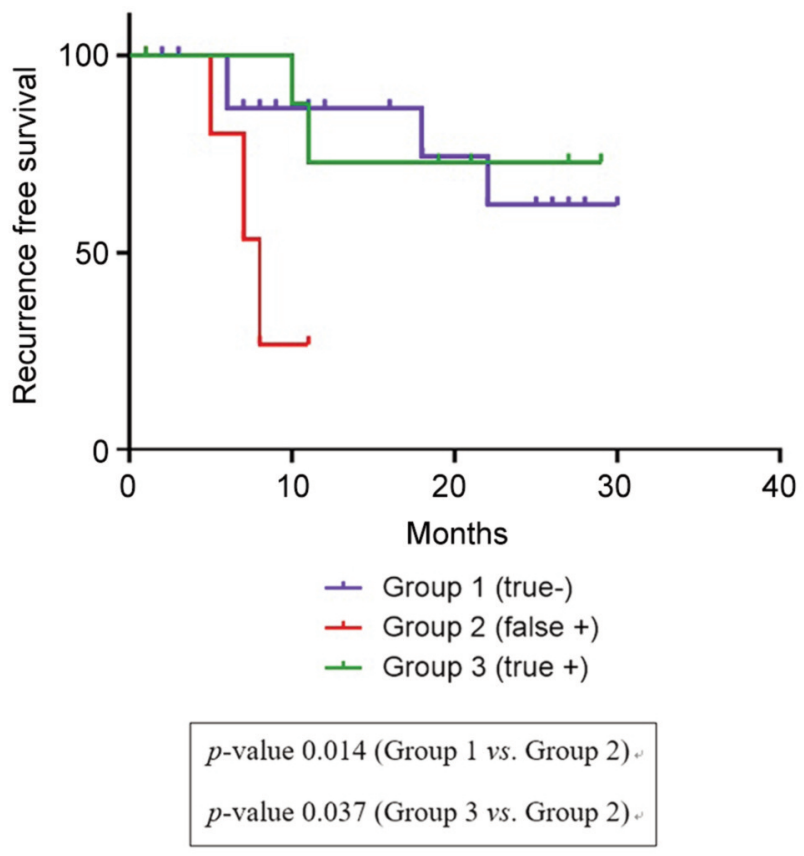

Figure 2. Kaplan-Meier curves for recurrence-free survival of patients with pathologic stage II disease. 
significantly higher white blood cell (WBC) counts, neutrophil counts, lymphocyte counts, and NLR. This could be possibly explained by intratumoral inflammatory processes associated with tumor FDG activity (26). Likewise, higher absolute platelet count and PLR could affect intratumoral inflammatory processes and induce high FDG uptake in PET-CT. NSCLC patients with falsepositive LN on PET-CT tend to have thrombocytosis and high PLR, resulting in tumor initiation and promotion. Thus, these patients need to be closely monitored for tumor recurrence.

In the present study, recurrence-free survival was significantly shorter for patients with false positive LN than for patients with true negative or true positive $\mathrm{LN}$ in pathologic stage II. However, false-positive LN was not significantly associated with recurrence-free survival in multivariate analysis. Elevated C-reactive protein and white blood cells at the time of diagnosis are independently associated with disease progression and shorter overall survival in advanced NSCLC (27). Likewise, in our study, patients with false-positive LN who had high absolute platelet count and PLR had shorter recurrence-free survival. High absolute platelet count and PLR are associated with inflammatory conditions (21). Early recurrence in NSCLC patients with false-positive $\mathrm{LN}$ is probably because inflammation can induce recurrence through its tumor promoting effects, including aiding proliferation and survival of malignant cells, promoting angiogenesis and metastasis, subverting adaptive immune responses, and altering responses to hormones and chemotherapeutic agents (28). The recurrence-free survival of patients with false-positive LN was shorter possibly because these stage II patients may have not received adjuvant chemotherapy or had low response to chemotherapy. Therefore, a large-scale study of survival analysis should be taken in the future.

In our study, false-positive LN was not a significant factor for recurrence-free survival. Current smoking and lymphatic invasion in NSCLC patients after curative resection were independent predictors of recurrence-free survival. These findings are consistent with those of previous studies (29, 30). Patients with persistent smoking have significant risks of all-cause mortality and recurrence in early stage lung cancer (29). Lymphovascular invasion is known to be associated with both high overall and distant recurrence rates as well as early tumor recurrence after curative surgery in NSCLC (30).

Previous studies have usually focused on PET-CT findings with false-positive LN. A recent study has reported that older age, bilateral hilar FDG uptake, and no LN swelling are significant factors related to false-positive LN metastases (31). In that study, there was a conflicting result about prognosis of patients with false-positive mediastinal LN on PET-CT. Patients with false-positive mediastinal LN had a low recurrence rate at 2 years after surgery, inconsistent with our study. Another retrospective cohort study has found that history of lung disease and central location of tumor are risk factors for false-positive mediastinal LN metastases (32). Published studies on clinicopathologic features of patients with false-positive mediastinal LN are scarce. Thus, our study could be significant because it elucidated various features and prognosis of NSCLC patients with false-positive LN on preoperative PET-CT.

This study has some limitations. First, it was a retrospective study with a relatively small sample size. However, this study could represent the real-world lung cancer population by enrolling consecutive patients. It could have been a more complete study if we had investigated whether taking adjuvant chemotherapy or in advance could affect responsiveness to treatment. Despite these limitations, the present study reflects real world practices. It showed that false-positivity could be a potential biomarker to predict poor prognosis

In conclusion, higher absolute platelet count, higher PLR, and lower proportion of lymphatic invasion were associated with false-positive mediastinal LN on preoperative FDG PETCT. Furthermore, recurrence-free survival was significantly shorter in patients with false-positive LNs on FDG PET-CT than in patients with same stage but true-positive or truenegative LNs. Preoperative biomarkers for predicting poor prognosis need to be investigated in the future.

\section{Conflicts of Interest}

The Authors have no conflicts of interest to declare in relation to this study.

\section{Authors' Contributions}

KYK: Conception and design, collection of data, data analysis and interpretation; HLP: conception and design, provision of study materials or patients, collection of data; HSK: administrative support, provision of study materials or patients, data analysis and interpretation; HYL: administrative support, provision of study materials or patients; IRY: provision of study materials or patients; SHL: administrative support, provision of study materials or patients; CDY: conception and design, collection of data, data analysis and interpretation.

\section{References}

1 Global Burden of Disease Cancer Collaboration: Global, regional, and national cancer incidence, mortality, years of life lost, years lived with disability, and disability-adjusted life-years for 29 cancer groups, 1990 to 2017: A systematic analysis for the global burden of disease study. JAMA Oncol 5(12): 17491768, 2019. PMID: 31560378. DOI: 10.1001/jamaoncol. 2019.2996

2 Park JY and Jang SH: Epidemiology of lung cancer in Korea: Recent trends. Tuberc Respir Dis (Seoul) 79(2): 58-69, 2016. PMID: 27064578. DOI: 10.4046/trd.2016.79.2.58 
3 Shlomi D, Ben-Avi R, Balmor GR, Onn A and Peled N: Screening for lung cancer: Time for large-scale screening by chest computed tomography. Eur Respir J 44(1): 217-238, 2014. PMID: 24525442. DOI: 10.1183/09031936.00164513

4 De Leyn P, Dooms C, Kuzdzal J, Lardinois D, Passlick B, RamiPorta R, Turna A, Van Schil P, Venuta F, Waller D, Weder W and Zielinski M: Preoperative mediastinal lymph node staging for non-small cell lung cancer: 2014 update of the 2007 ESTS guidelines. Transl Lung Cancer Res 3(4): 225-233, 2014. PMID: 25806304. DOI: 10.3978/j.issn.2218-6751.2014.08.05

5 Silvestri GA, Gould MK, Margolis ML, Tanoue LT, McCrory D, Toloza E, Detterbeck F and American College of Chest Physicians: Noninvasive staging of non-small cell lung cancer: ACCP evidenced-based clinical practice guidelines (2nd edition) Chest 132(3 Suppl): 178S-201S, 2007. PMID: 17873168. DOI: 10.1378/chest.07-1360

6 Um SW, Kim HK, Jung SH, Han J, Lee KJ, Park HY, Choi YS, Shim YM, Ahn MJ, Park K, Ahn YC, Choi JY, Lee KS, Suh GY, Chung MP, Kwon OJ, Kim J and Kim H: Endobronchial ultrasound versus mediastinoscopy for mediastinal nodal staging of non-small-cell lung cancer. J Thorac Oncol 10(2): 331-337, 2015. PMID: 25611227. DOI: $10.1097 / J T O .0000000000000388$

7 Varela-Lema L, Fernández-Villar A and Ruano-Ravina A: Effectiveness and safety of endobronchial ultrasoundtransbronchial needle aspiration: A systematic review. Eur Respir J 33(5): 1156-1164, 2009. PMID: 19407050. DOI: 10.1183/ 09031936.00097908

8 Feng M, Yang X, Ma Q and He Y: Retrospective analysis for the false positive diagnosis of PET-CT scan in lung cancer patients. Medicine (Baltimore) 96(42): e7415, 2017. PMID: 29049175. DOI: 10.1097/MD.0000000000007415

9 Kaseda K, Watanabe K, Asakura K, Kazama A and Ozawa Y: Identification of false-negative and false-positive diagnoses of lymph node metastases in non-small cell lung cancer patients staged by integrated (18F-)fluorodeoxyglucose-positron emission tomography/computed tomography: A retrospective cohort study. Thorac Cancer 7(4): 473-480, 2016. PMID: 27385991. DOI: 10.1111/1759-7714.12358

10 Nomori H, Watanabe K, Ohtsuka T, Naruke T, Suemasu K and Uno K: The size of metastatic foci and lymph nodes yielding false-negative and false-positive lymph node staging with positron emission tomography in patients with lung cancer. J Thorac Cardiovasc Surg 127(4): 1087-1092, 2004. PMID: 15052206. DOI: 10.1016/j.jtcvs.2003.08.010

11 Choi WH, Yoo IeR, O JH, Kim TJ, Lee KY and Kim YK: Is the Glut expression related to FDG uptake in PET/CT of non-small cell lung cancer patients? Technol Health Care 23 Suppl 2: S311S318, 2015. PMID: 26410497. DOI: 10.3233/THC-150967

12 Chang JM, Lee HJ, Goo JM, Lee HY, Lee JJ, Chung JK and Im JG: False positive and false negative FDG-PET scans in various thoracic diseases. Korean J Radiol 7(1): 57-69, 2006. PMID: 16549957. DOI: $10.3348 / \mathrm{kjr} .2006 .7 .1 .57$

13 Berghmans T, Dusart M, Paesmans M, Hossein-Foucher C, Buvat I, Castaigne C, Scherpereel A, Mascaux C, Moreau M, Roelandts M, Alard S, Meert AP, Patz EF Jr, Lafitte JJ, Sculier JP and European Lung Cancer Working Party for the IASLC Lung Cancer Staging Project: Primary tumor standardized uptake value (SUVmax) measured on fluorodeoxyglucose positron emission tomography (FDG-PET) is of prognostic value for survival in non-small cell lung cancer (NSCLC): A systematic review and meta-analysis (MA) by the European Lung Cancer Working Party for the IASLC Lung Cancer Staging Project. J Thorac Oncol 3(1): 6-12, 2008. PMID: 18166834. DOI: $10.1097 /$ JTO.0b013e31815e6d6b

14 Lin $\mathrm{J}$ and Fernandez F: Indications for invasive mediastinal staging for non-small cell lung cancer. J Thorac Cardiovasc Surg 156(6): 2319-2324, 2018. PMID: 30146229. DOI: 10.1016/ j.jtcvs.2018.07.027

15 Yeo CD, Kim JW, Kim KH, Ha JH, Rhee CK, Kim SJ, Kim YK, Park CK, Lee SH, Park MS and Yim HW: Detection and comparison of EGFR mutations in matched tumor tissues, cell blocks, pleural effusions, and sera from patients with NSCLC with malignant pleural effusion, by PNA clamping and direct sequencing. Lung Cancer 81(2): 207-212, 2013. PMID: 23726527. DOI: 10.1016/j.lungcan.2013.04.023

16 Kim TJ, Park CK, Yeo CD, Park K, Rhee CK, Kim J, Kim SJ, Lee SH, Lee KY and Yoon HK: Simultaneous diagnostic platform of genotyping EGFR, KRAS, and ALK in 510 Korean patients with non-small-cell lung cancer highlights significantly higher ALK rearrangement rate in advanced stage. J Surg Oncol 110(3): 245-251, 2014. PMID: 24888607. DOI: 10.1002/jso.23646

17 Lee J, Park CK, Yoon HK, Sa YJ, Woo IS, Kim HR, Kim SY and Kim TJ: PD-L1 expression in ROS1-rearranged non-small cell lung cancer: A study using simultaneous genotypic screening of EGFR, ALK, and ROS1. Thorac Cancer 10(1): 103-110, 2019. PMID: 30475455. DOI: 10.1111/1759-7714.12917

18 Franco AT, Corken A and Ware J: Platelets at the interface of thrombosis, inflammation, and cancer. Blood 126(5): 582-588, 2015. PMID: 26109205. DOI: 10.1182/blood-2014-08-531582

$19 \mathrm{Yu} \mathrm{D,} \mathrm{Liu} \mathrm{B,} \mathrm{Zhang} \mathrm{L} \mathrm{and} \mathrm{DU} \mathrm{K:} \mathrm{Platelet} \mathrm{count} \mathrm{predicts}$ prognosis in operable non-small cell lung cancer. Exp Ther Med 5(5): 1351-1354, 2013. PMID: 23737877. DOI: 10.3892/ etm.2013.1003

20 Gonzalez Barcala FJ, Garcia Prim JM, Moldes Rodriguez M, Alvarez Fernandez J, Rey Rey MJ, Pose Reino A and Valdes Cuadrado L: Platelet count: Association with prognosis in lung cancer. Med Oncol 27(2): 357-362, 2010. PMID: 19381892. DOI: $10.1007 / \mathrm{s} 12032-009-9217-9$

21 Zhao QT, Yuan Z, Zhang H, Zhang XP, Wang HE, Wang ZK and Duan GC: Prognostic role of platelet to lymphocyte ratio in nonsmall cell lung cancers: A meta-analysis including 3,720 patients. Int J Cancer 139(1): 164-170, 2016. PMID: 26915723. DOI: $10.1002 / \mathrm{ijc} .30060$

22 Lim JU, Yeo CD, Kang HS, Park CK, Kim JS, Kim JW, Kim SJ and Lee SH: Elevated pretreatment platelet-to-lymphocyte ratio is associated with poor survival in stage IV non-small cell lung cancer with malignant pleural effusion. Sci Rep 9(1): 4721, 2019. PMID: 30886226. DOI: 10.1038/s41598-019-41289-9

23 Liu H, Wu Y, Wang Z, Yao Y, Chen F, Zhang H, Wang Y and Song Y: Pretreatment platelet-to-lymphocyte ratio (PLR) as a predictor of response to first-line platinum-based chemotherapy and prognosis for patients with non-small cell lung cancer. J Thorac Dis 5(6): 783-789, 2013. PMID: 24409356. DOI: 10.3978/j.issn.2072-1439.2013.12.34

24 Grivennikov SI, Greten FR and Karin M: Immunity, inflammation, and cancer. Cell 140(6): 883-899, 2010. PMID: 20303878. DOI: 10.1016/j.cell.2010.01.025

25 Jeong E, Hyun SH, Moon SH, Cho YS, Kim BT and Lee KH: Relation between tumor FDG uptake and hematologic prognostic indicators in stage I lung cancer patients following curative 
resection. Medicine (Baltimore) 96(5): e5935, 2017. PMID 28151879. DOI: $10.1097 / \mathrm{MD} .0000000000005935$

26 Kim M, Achmad A, Higuchi T, Arisaka Y, Yokoo H, Yokoo S and Tsushima $\mathrm{Y}$ : Effects of intratumoral inflammatory process on 18F-FDG uptake: Pathologic and comparative study with $18 \mathrm{~F}$-fluoro- $\alpha$-methyltyrosine $\mathrm{PET} / \mathrm{CT}$ in oral squamous cell carcinoma. J Nucl Med 56(1): 16-21, 2015. PMID: 25476535. DOI: $10.2967 /$ jnumed.114.144014

27 Kasymjanova G, MacDonald N, Agulnik JS, Cohen V, Pepe C, Kreisman H, Sharma R and Small D: The predictive value of pre-treatment inflammatory markers in advanced non-small-cell lung cancer. Curr Oncol 17(4): 52-58, 2010. PMID: 20697515. DOI: $10.3747 /$ co.v17i4.567

28 Mantovani A, Allavena P, Sica A and Balkwill F: Cancer-related inflammation. Nature 454(7203): 436-444, 2008. PMID: 18650914. DOI: 10.1038 /nature07205

29 Parsons A, Daley A, Begh R and Aveyard P: Influence of smoking cessation after diagnosis of early stage lung cancer on prognosis: Systematic review of observational studies with metaanalysis. BMJ 340: b5569, 2010. PMID: 20093278. DOI: 10.1136/bmj.b5569.
30 Park C, Lee IJ, Jang SH and Lee JW: Factors affecting tumor recurrence after curative surgery for NSCLC: Impacts of lymphovascular invasion on early tumor recurrence. J Thorac Dis 6(10): 1420-1428, 2014. PMID: 25364519. DOI: 10.3978/ j.issn.2072-1439.2014.09.31

31 Endoh H, Yamamoto R, Ichikawa A, Shiozawa S, Nishizawa N, Satoh Y and Oriuchi N: Clinicopathologic significance of falsepositive lymph node status on FDG-PET in lung cancer. Clin Lung Cancer: 2020. PMID: 32654926. DOI: 10.1016/j.cllc. 2020.05.002

32 Kaseda K, Watanabe K, Asakura K, Kazama A and Ozawa Y: Identification of false-negative and false-positive diagnoses of lymph node metastases in non-small cell lung cancer patients staged by integrated (18F-)fluorodeoxyglucose-positron emission tomography/computed tomography: A retrospective cohort study. Thorac Cancer 7(4): 473-480, 2016. PMID: 27385991. DOI: $10.1111 / 1759-7714.12358$

Received February 26, 2021

Revised March 15, 2021 Accepted March 16, 2021 